\title{
Tropospheric biennial oscillation of summer monsoon rainfall over East Asia and its association with ENSO
}

\author{
Yunyun Liu · Zeng-Zhen Hu • Arun Kumar • \\ Peitao Peng $\cdot$ Dan C. Collins $\cdot$ Bhaskar Jha
}

Received: 25 March 2014 / Accepted: 21 November 2014 / Published online: 9 December 2014

(C) The Author(s) 2014. This article is published with open access at Springerlink.com

\begin{abstract}
Based on observations and a set of Atmospheric Model Intercomparison Project (AMIP)-type simulations, the climatic characteristics and dominant spatial patterns of summer rainfall on tropospheric biennial oscillation (TBO) time scales over the East Asian summer monsoon (EASM) region were examined, and the association with sea surface temperature anomalies (SSTAs) and El Niño-Southern Oscillation were analyzed. It was noted that to some extent, the AMIP run successfully simulated the spatial distribution and amplitude of the observed TBO component. Furthermore, the AMIP ensemble mean increased the fraction of total variance of the TBO component, suggesting that SSTAs may have a rainfall response over the EASM region on TBO time scales. The analysis also indicated that a spatial pattern of rainfall on TBO time scales with opposite variations between northern and southern China showed a consistent and robust relationship with SSTAs in the tropical Pacific Ocean in both the AMIP simulations and observations. Statistically,when an El Niño (La Niña) develops, northern China favors dry (wet) conditions and southern China favors wet (dry) conditions at TBO time scales.
\end{abstract}

\section{Y. Liu $(\square)$}

National Climate Center, Chinese Meteorological Administration, No. 46 Zhong-Guan-Cun South Avenue, Beijing 100081, People's Republic of China

e-mail: liuyuny@cma.gov.cn

Z.-Z. Hu $\cdot$ A. Kumar $\cdot$ P. Peng $\cdot$ D. C. Collins $\cdot$ B. Jha Climate Prediction Center, NCEP/NOAA, College Park, MD 20740, USA

B. Jha

Innovim, LLC, Greenbelt, MD, USA
Keywords Tropospheric biennial oscillation (TBO) . Summer monsoon rainfall $\cdot$ East Asia $\cdot$ ENSO . Atmospheric Model Intercomparison Project (AMIP)

\section{Introduction}

There is a significant fraction of variability at biennial oscillation scales in tropospheric circulation and precipitation in the monsoon region. This phenomenon was termed the tropospheric biennial oscillation (TBO) (Meehl 1994, 1997) to distinguish it from the quasi-biennial oscillation in the stratosphere (Reed et al. 1961). The studies of TBO over the Asian monsoon region began in the 1980s. For example, Mooley and Parthasarathy (1984) noted that all India rainfall averaged from June to September has a significant component of TBO. Later, some TBO signals were also found in East Asian summer monsoon (EASM) rainfall (Tian and Yasunari 1992; Chang and Li 2000; Chang et al. 2000; Ding 2007), including some regions of the mainland of China (Huang 1988; Wang et al. 1995; Nitta and Hu 1996; Zhan et al. 2013). In fact, TBO commonly exists in atmospheric circulations, tropical sea surface temperature (SST) and other surface meteorological elements in the Indian and Pacific Oceans as well as whole Asian-Australian monsoon region (Rasmusson et al. 1990; Yasunari 1990; Shen and Lau 1995; Meehl and Arblaster 2002; Meehl et al. 2003; Qiao et al. 2005; Li et al. 2011; Liu and Ding 2012; Liu et al. 2013). Moreover, the TBO component in the EASM region also experienced interdecadal variations. It was intensified after the middle of the 1970s in the variations of summer rainfall and temperature anomalies along the middle and lower reaches of the Yangtze River (Nitta and Hu 1996; Hu 1999). 
The physical mechanism of the TBO over the Asian monsoon region is still not well understood. One hypothesis proposed is that TBO is a result of ocean-atmospheric interaction. For example, Shen and Lau (1995) and Lau and Yang (1997) argued that air-sea coupling over the region from the South China Sea to the western Pacific warm pool is associated with TBO of EASM variations. Alternatively, Rasmusson et al. (1990) and Yasunari (1990) suggested the contribution by the central and eastern tropical Pacific Ocean associated with El Niño-Southern Oscillation (ENSO) to TBO of the Asian summer monsoon variations. Meehl and Arblaster (2002) emphasized that the TBO is a fundamental feature of the coupled climate system over the entire Indian-Pacific region, and the oceanatmospheric interaction over the region was the dominant contributor to Asian-Australian monsoon variations at TBO time scales. They noted an intrinsic coupling of the anomalous strength of the convective maximum in the seasonal cycle over Australasia to surface wind forcing, ocean dynamical response, and associated SST anomalies that feed back to the strength of the convective maximum, and so on. The consequent feedback to the monsoon circulation by the SSTAs in the tropical Pacific and Indian Oceans leads to the TBO in the Asian-Australian monsoon region.

Chang and $\mathrm{Li}$ (2000) and $\mathrm{Li}$ et al. (2001), however, argued that the TBO may be a local air-sea coupled phenomenon. Supporting evidence is that the TBO signal over the Indian Ocean is still present without the role of remote forcing, such as equatorial Pacific SSTAs. In the local coupling paradigm, the feedbacks between the Indian Ocean SSTA and the Asian monsoon, between the surface wind and evaporation, and between the wind stress and ocean thermocline all contribute to TBO-like variations. Nevertheless, both Meehl and Arblaster (2002) and Meehl et al. (2003) noted that without the influence of ENSO, TBO in the Asian-Australian monsoon region would be weakened. Thus, these results suggest that the variations of East Asian summer climate at TBO time scales are largely associated with local air-sea interaction and remote forcing, such as ENSO, may affect the intensity of the TBO signal to some extent.

In this study, the climatic features of summer rainfall and its TBO component over the Asian summer monsoon regions were first analyzed in the observations and in the Atmospheric Model Intercomparison Project (AMIP) simulations to assess the fidelity of the AMIP simulations. Then, the leading patterns of rainfall in the EASM region at TBO time scales, isolated using the empirical orthogonal function (EOF) technique, are compared between the observations and AMIP simulations to identify robust and consistent spatial patterns. Lastly, the association of robust EOF pattern evolution with global SST is examined to further identify the role of SSTAs, particularly the association with ENSO, in the TBO of summer rainfall in East Asia.

The paper is organized as follows. Section "AMIP run, data, and approaches" provides a description of data, AMIP simulations, and approaches used in the study. Section "Analysis of mean state" shows the climatological characteristics of the JJA rainfall and its TBO component in the observations and AMIP simulation. Section "Leading modes of TBO in summer rainfall" identifies the robust and consistent EOF modes of rainfall in the EASM region. Section "Association of ENSO with leading EOF modes" examines their connection with global SST, particularly with ENSO evolution. Summary and discussions are given in the section "Summary and discussion".

\section{AMIP run, data, and approaches}

The AMIP-type simulations are from the atmospheric component (Global Forecast System: GFS) of the Climate Forecast System version 2 model of the National Centers for Environmental Prediction (Kumar et al. 2012; Saha et al. 2014). In GFS, the sub-grid physical process includes simplified Arakawa Schubert deep convection and shallow convection with an updated mass flux scheme. The model has a horizontal resolution of T126 and 64 vertical levels extending from the surface to $0.26 \mathrm{hPa}$. For each simulation, the same observed evolution of SST, sea ice extent, and observed time-evolving greenhouse gas concentrations were specified as external forcing. AMIP simulations consist of 18 integrations (ensemble members) with slightly different atmospheric initial conditions from 1 Jan. 1957. Monthly mean precipitation rate (Prate) from the model is analyzed in this work.

The corresponding observational data includes the Climate Prediction Center monthly precipitation analysis over the global land on a $0.5^{\circ} \times 0.5^{\circ}$ resolution (Chen et al. 2002), and the Extended Reconstructed SST dataset (ERSSTv3b) at $2^{\circ} \times 2^{\circ}$ resolution (Smith et al. 2008). The analysis period is from 1957 to 2011.

In the context of Asian monsoon rainfall, the TBO is defined as the tendency for a relatively strong monsoon to be followed by a relatively weak one, and vice versa (Meehl and Arblaster 2002). The TBO component is isolated from the June-July-August (JJA) total rainfall by removing the 3-y running mean. In addition, monthly SST data are filtered with a 24-36 month band-pass filter prior to calculating the lead-lag correlations with the principle component (PC) of the EOF pattern of filtered rainfall in JJA. To identify the leading spatial patterns of TBO rainfall in the EASM region and their evolution, the EOF technique is applied by using the co-variance matrix of JJA rainfall at TBO time scales with area (latitude) weighting (North et al. 

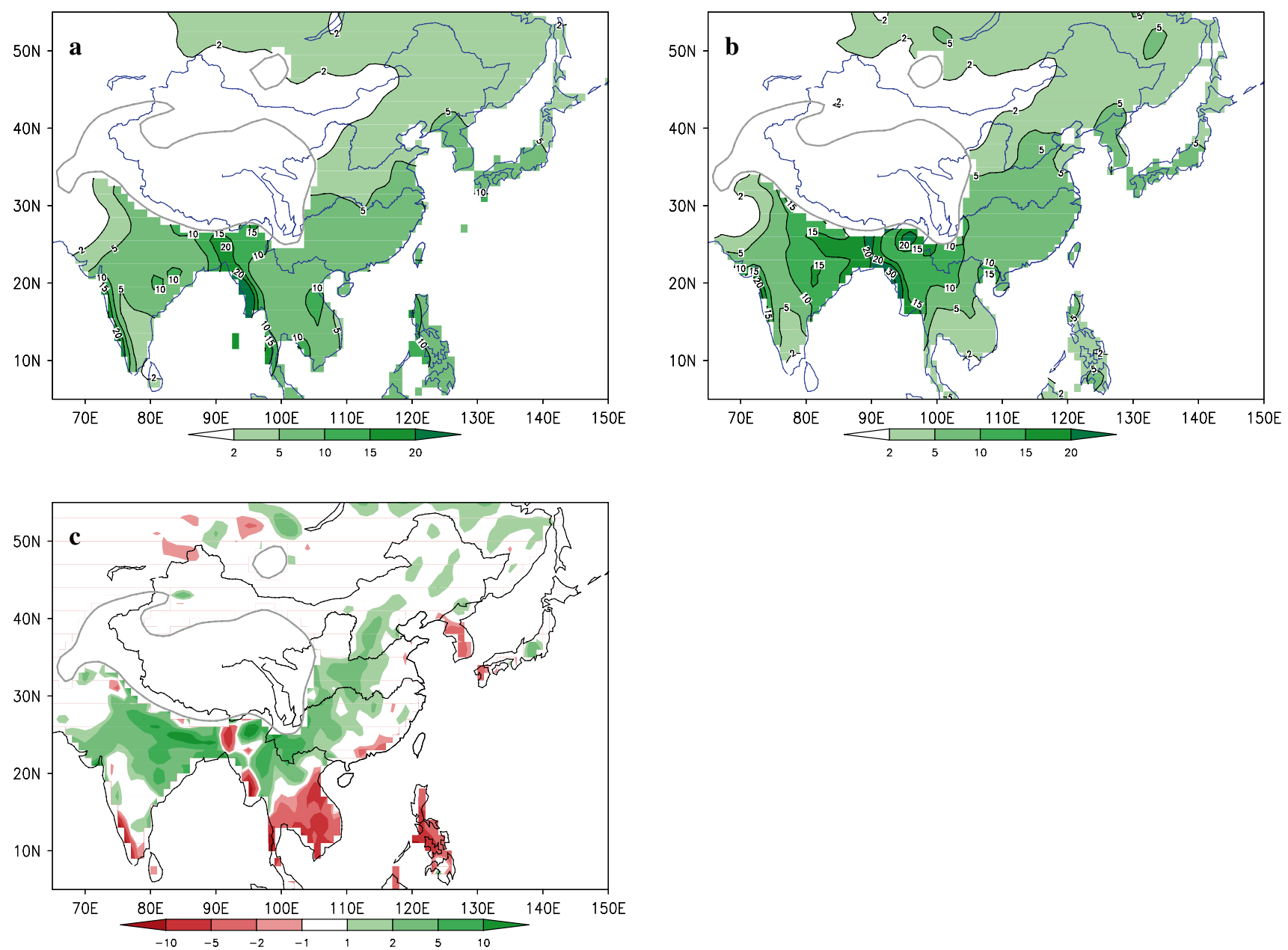

Fig. 1 Climatological summer (JJA) rainfall (mm/day) of a the observations and $\mathbf{b}$ the AMIP run, and $\mathbf{c}$ the difference of (b)-(a). The gray line represents Tibetan Plateau

1982). In addition, linear regression is also used to examine the connection between SSTAs and TBO rainfall anomalies in the EASM region.

\section{Analysis of mean state}

In model simulations, an accurate depiction of the mean climate may be essential to producing a realistic TBO signal. In this section, the climate mean, and the variance of JJA rainfall and its TBO component are compared for the observations and the AMIP simulations to assess fidelity of the model.

\subsection{Climatological mean distribution}

Over a broad Asian summer monsoon region, Fig. 1 shows the 55-y mean (1957-2011) climatological summer (JJA) rainfall from the observations (Fig. 1a), AMIP simulations averaged over all 18 members (Fig. 1b), and model biases relative to the observations (Fig. 1c). The observed seasonal mean rainfall is generally above $5 \mathrm{~mm} /$ day over most of the region except for North China. Climatologically, rainfall over the region is characterized by heavy rainfall centers mainly located near the western coast and northeast of India, the northern Bay of Bengal, the Indochina Peninsula, and the Philippines (Fig. 1a).

The spatial distribution of the observed climatological rainfall is well captured by the model (Fig. 1b). The overall pattern of differences (biases) between model simulated and observed climatology (Fig. 1c) is dominated by a wet bias to the south and east of the Tibetan Plateau, including the north of India and the Indochina Peninsula, and central and western parts of East China. Meanwhile, dry biases are present over the southern Indochina Peninsula and most of the Philippines, as well as over Korea, southern Japan, and the southeastern coast of China (Fig. 1c). The reasons for these biases are still unclear, particularly for 

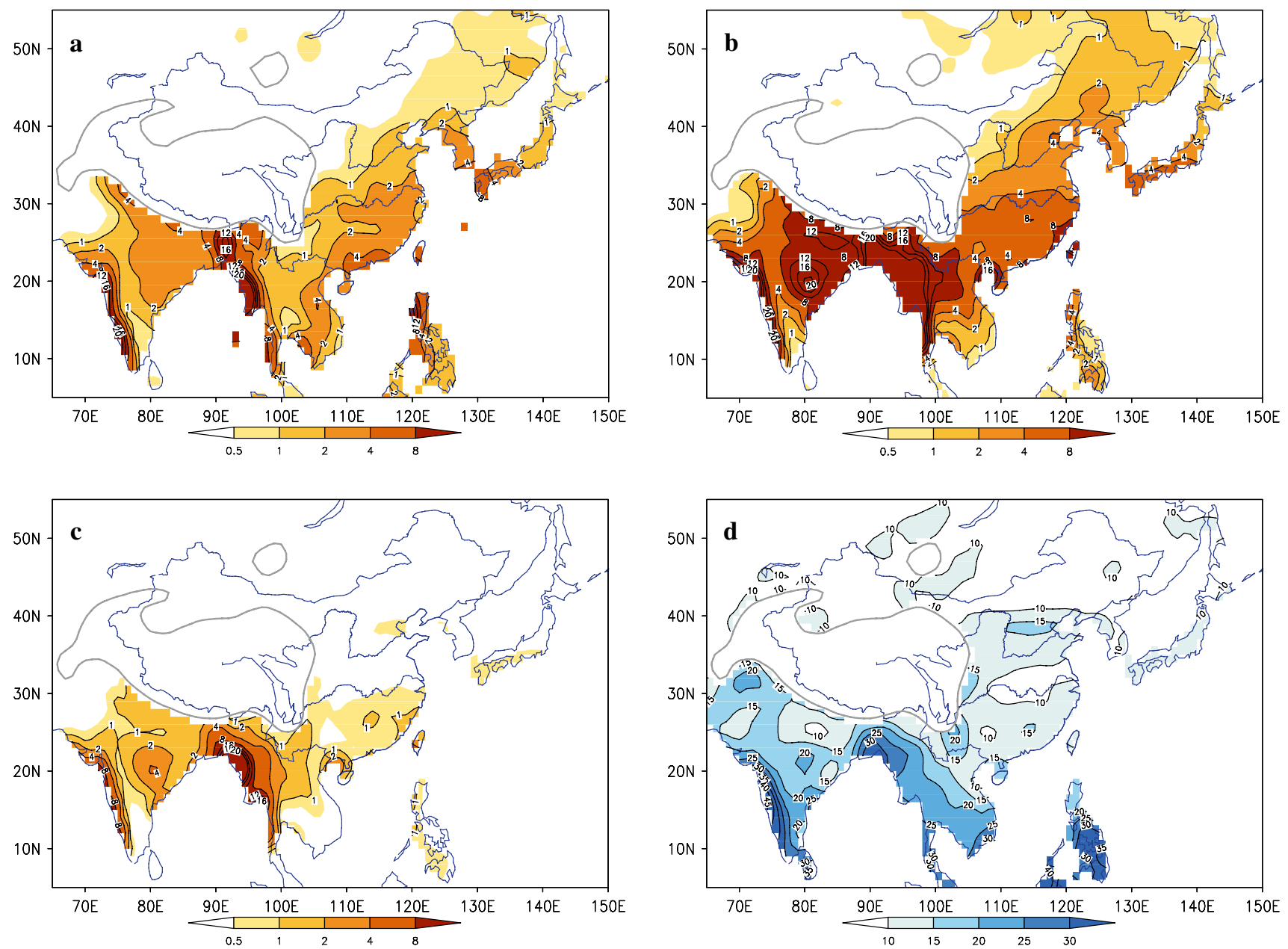

Fig. 2 Variance of JJA rainfall anomalies in a the observation, b AMIP individual members, $\mathbf{c}$ the AMIP ensemble mean, and $\mathbf{d}$ the variance ratio between (c) and (b). The units for shading and contours are $\mathrm{mm}^{2} / \mathrm{day}^{2}$ in $(\mathbf{a}-\mathbf{c})$ and $\%$ in (d). The gray line represents Tibetan Plateau

the pronounced wet bias around the Tibetan Plateau. The bias is larger in low latitudes than in high latitudes, which is expected as the total rainfall amount decreases from low to high latitudes. Over the EASM region, the model bias is smaller than in the tropics.

\subsection{Variance of the monsoon rainfall}

Variances of the monsoon rainfall from observations and model simulations are shown in Fig. 2. The results for the observed rainfall show that larger variability in JJA rainfall generally collocates with major centers of mean rainfall amounts (Figs. 1a, 2a), meaning that large (small) variability corresponds to large (small) mean rainfall amount. Figure $2 b, c$ show the corresponding variance of summer monsoon rainfall from the AMIP runs, calculated for each AMIP member individually first (Fig. 2b) and then averaged for all 18 members (Fig. 2c). The spatial features of the observed variability are well captured by the model.
However, the variability is generally overestimated over northern India, the northeastern Bay of Bengal, the central Indochina Peninsula, southern China and the northern Philippines (Fig. 2a, b).

Compared with Fig. 2a, b, the amplitude of variance decreases significantly, when rainfall from the 18 members is averaged first and then variance is calculated based on the ensemble mean (Fig. 2c). The variance of the AMIP ensemble mean (Fig. 2c) is largely the result of interannual variability forced by SST variations that are common for all AMIP simulations, because the contribution from random internal variability is mostly canceled out by averaging of ensemble members (Kumar et al. 2001). Nevertheless, it is noted that the ensemble mean (Fig. 2c) reproduces the centers of large variability although with smaller amplitudes in the tropics and subtropics, such as for the western coast and north of India, the northwestern part of the Indochina Peninsula, and southern China, implying a possible association of SSTAs with rainfall variability over these regions. 
Figure $2 \mathrm{~d}$ is the ratio of rainfall variance between the AMIP 18-member average and the ensemble mean (ratio of Fig. 2b, c). Usually, from a pure statistical argument, the variance of the ensemble mean of an 18-member ensemble should be about 1/18 (5-6\%) that of a single member if all the variability is due to random internal variability (Wu et al. 2004). It is noted that the variance ratio between the ensemble mean of the TBO component and individual AMIP simulations is larger than $10 \%$ over most of the monsoon region in Fig. 2d. This is an indication that the interannual variation (including TBO component) of Asian summer monsoon rainfall may partially be associated with external forcing, such as by SST.

\subsection{Variance and fraction of TBO component of monsoon rainfall}

Considering that the Asian summer monsoon rainfall has a significant fraction of variability at TBO time scales (Lau and $\mathrm{Wu}$ 2000; Meehl and Arblaster 2002; Li et al. 2006), we compute the variance of the TBO component and its variance fraction relative to raw (unfiltered) data for the observations, for the individual AMIP simulations averaged, and for the ensemble mean, respectively (Fig. 3). The observations show that the variance distribution pattern of the TBO component is similar to that of the total monsoon rainfall, especially for its primary centers, which are nearly collocated (Figs. 2a, 3a), suggesting that a large (small) total rainfall amount corresponds to a large (small) amount of rainfall at TBO time scales. On average, the variance fraction of TBO relative to that of raw data usually exceeds $35 \%$, and reaches $45 \%$ over some regions, such as northeast India, the central Philippines, the southern Indochina Peninsula, the central Yangtze River basin, and most of North China (Fig. 3a, d). This implies that TBO is an important component of summer monsoon interannual variations in these regions.

The AMIP results well reproduce the spatial distribution of TBO variance (Fig. 3a, b), while the fraction of variance of the TBO component to the total rainfall is underestimated compared with the observations (Fig. 3d, e). The distribution of the fraction in the observations (Fig. 3d) shows clear spatial inhomogeneity with large values in the central part of East China, while the AMIP simulations display an almost spatially homogeneous distribution (Fig. 3e). The spatially homogeneous distribution may imply that internal dynamical processes play a dominant role in TBO time scale variations in each individual ensemble member. Interestingly, although the ensemble mean (Fig. 3c) has much smaller amplitudes for the variance of TBO rainfall, the amplitude and spatial distribution of the variance ratio of TBO to raw data is much closer to the observations compared with that of the AMIP 18-member average
(Fig. 3d-f). This result suggests that the TBO signal in the EASM region is enhanced by eliminating the atmospheric internal variability through the ensemble mean. This indicates the contribution of SST to the TBO time scale variations and is consistent with Meehl et al. (2003). The connection of TBO variation and SST will be further examined in the next two sections.

\section{Leading modes of TBO in summer rainfall}

The comparison in the previous section suggests that the AMIP run captures the spatial distribution of the basic climate states of summer rainfall and its TBO component over the Asian monsoon region. This provides a justification for further analyzing the leading modes of the TBO component of rainfall in the EASM region and their connection with SSTA. The spatial domain for the EOF analysis is chosen to be from 22.5 to $54^{\circ} \mathrm{N}$ and from 105 to $145^{\circ} \mathrm{E}$, so as to focus on the EASM region (Wang et al. 2001). As in the previous section, the AMIP simulations are handled in two ways. One is to concatenate 18 members of the AMIP run as one long time series, and then do the EOF analysis. Such an analysis is equivalent for observations and is influenced by both the external forcing (such as SST) and internal atmospheric variability. The other is to do EOF analysis for the ensemble mean of 18 members of the AMIP run. The results from such EOF analysis amplify the response of the atmosphere to SSTA, since the internal variability is suppressed by the ensemble averaging. Pattern correlations between the EOF patterns from model simulations and those from the observations are computed to compare their spatial similarity.

\subsection{EOF for observations and individual AMIP simulations}

Figure 4 shows the first four EOF modes of the TBO component of JJA rainfall in the observations, which explain $19.8,14.6,11.7$ and $9.9 \%$ of the total variance of the TBO component, respectively. The accumulative explained variance by the first four modes is $56 \%$, which are independent from each other according to North's et al. (1982) significance test. EOF1 (Fig. 4a) is a tripole pattern ("+, -, + "), which is also a typical pattern of total summer rainfall (Nitta and Hu 1996; Ding et al. 2008) with opposite variations of rainfall along the Yangtze River basin and most of Korea and Japan to rainfall to the north and south. EOF2 (Fig. 4b) represents opposite variations of rainfall over the regions from the middle of the Yangtze River to Northeast China via the HuaiHe River basin to rainfall in southeastern China, southern Korea and Japan. EOF3 (Fig. 4c) has some similarities with EOF1 in eastern China. EOF4 is a dipole 

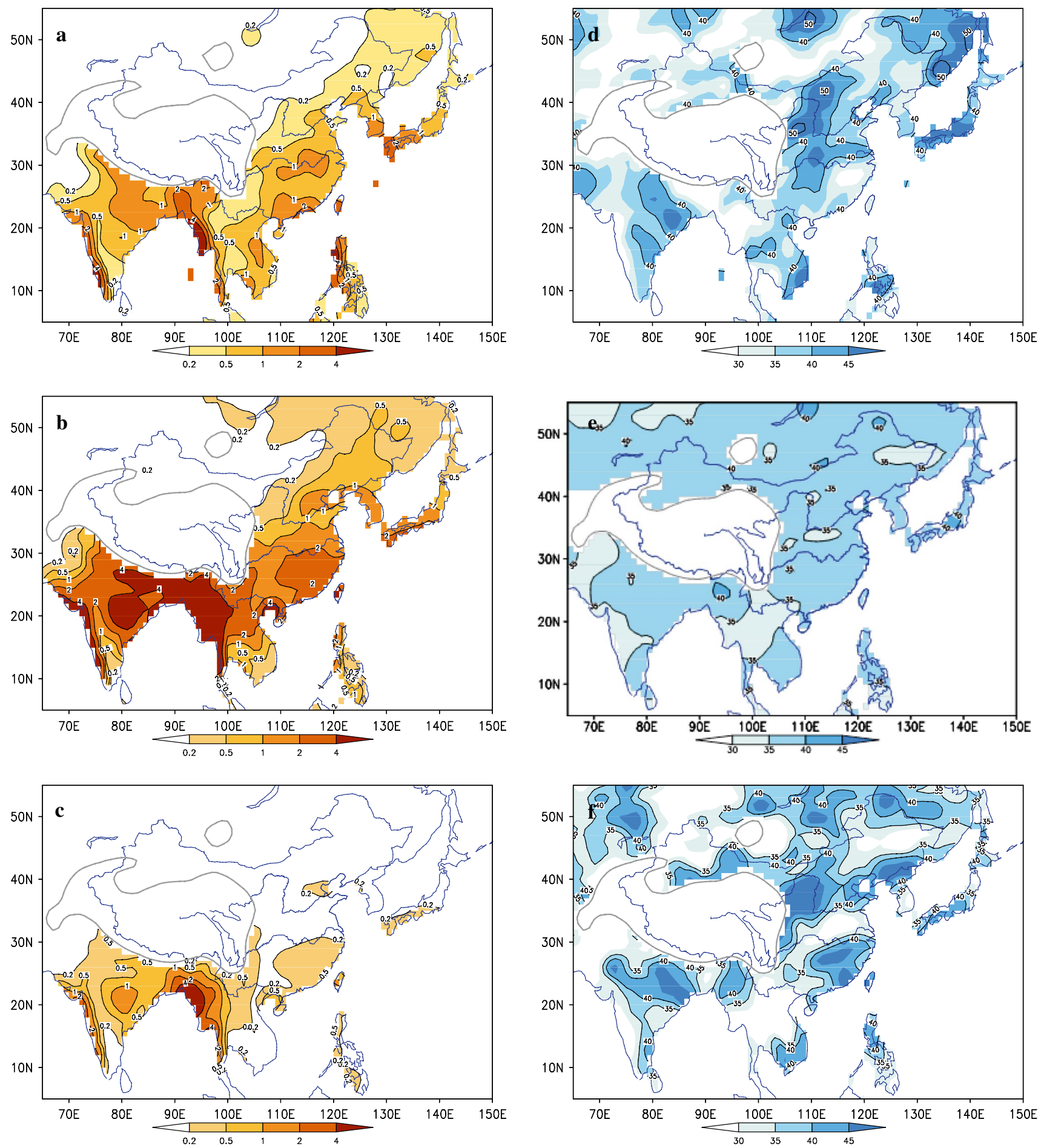

Fig. 3 Variance of the TBO component of JJA rainfall and its ratio to the variance of raw data in $\mathbf{a}, \mathbf{d}$ observation, $\mathbf{b}, \mathbf{e}$ the AMIP 18-member average and $\mathbf{c}, \mathbf{f}$ the AMIP ensemble mean. The units for shading

and contours are $\mathrm{mm}^{2} / \mathrm{day}^{2}$ in $(\mathbf{a}-\mathbf{c})$ and $\%$ in $(\mathbf{d}-\mathbf{f})$. The gray line represents Tibetan Plateau

Figure 5 shows the corresponding EOF modes of the pattern ("+, -"), which is another typical pattern for total summer rainfall that usually occurs during an ENSO year (Wang et al. 2000; Ding et al. 2008), with opposite variations between northern and southern China. AMIP simulations based on individual members. Compared with the observations (Fig. 4), it is noted that the first three EOF modes from the AMIP run have corresponding 

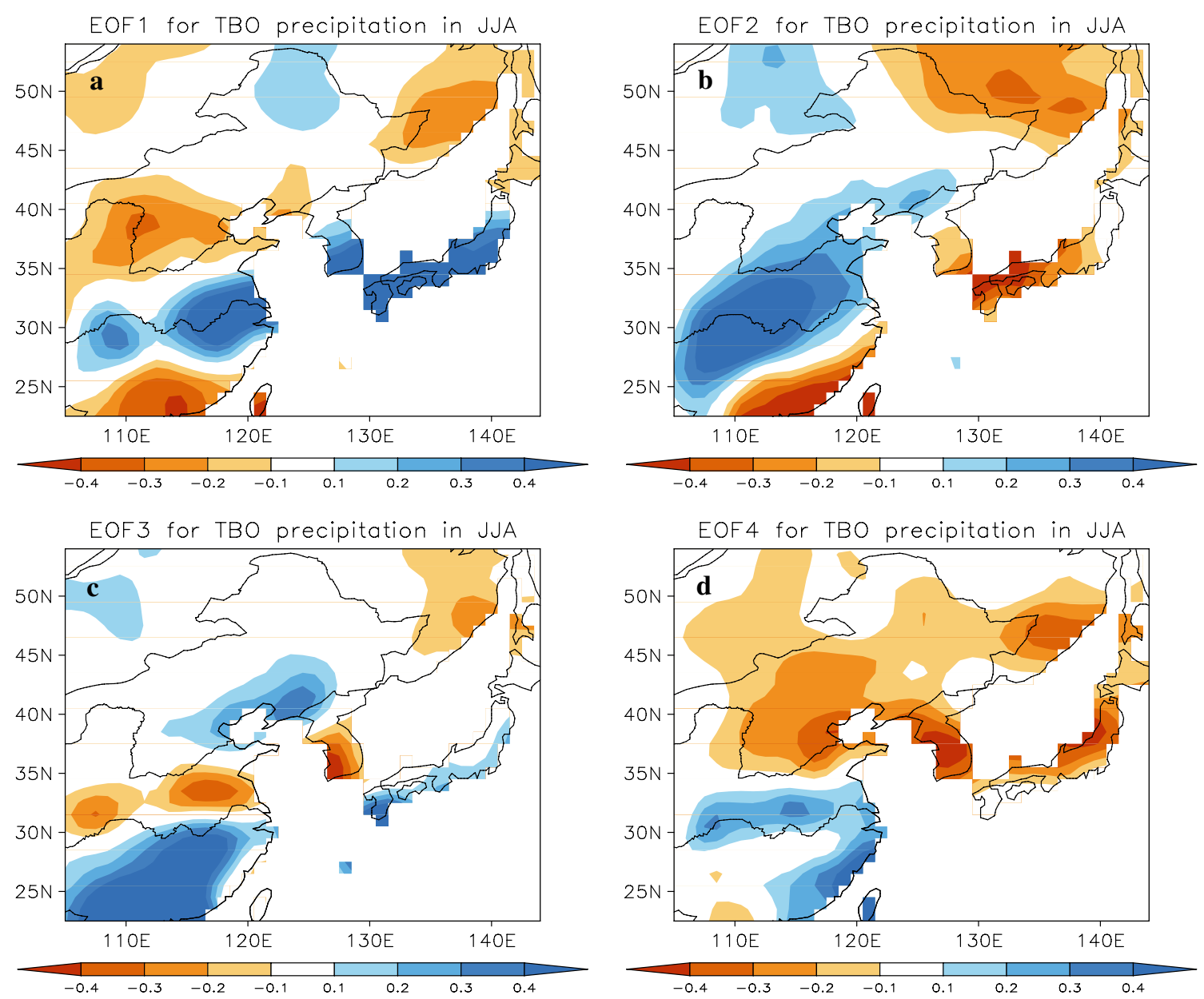

Fig. 4 The first four EOF modes of JJA rainfall in the observations. EOFs 1-4 explain 19.8, 14.6, 11.7 and $9.9 \%$ of the total variance of TBO component, respectively

modes in the observations, though the sequence and amplitudes of the EOF modes are somewhat different. For example, EOF1 from the AMIP run (Fig. 5a) is similar to EOF4 from the observations (Fig. 4d) with a pattern correlation between the two EOFs of 0.55 (Table 1). Similarly, EOF2 of the AMIP run has a significant pattern correlation coefficient of 0.68 with EOF1 of the observations, while EOF3 of the AMIP run corresponds to EOF2 of the observations with a pattern correlation coefficient of 0.57 (Table 1). All of these pattern correlation coefficients exceed the 0.01 significance level.

\subsection{EOF analysis for ensemble mean}

To isolate the impact of SSTA on TBO, we first make the ensemble mean of the 18 members of the AMIP run, and then compute the EOF modes (Fig. 6). Compared with the results of the 18 individual members of the AMIP run (Fig. 5) and the observations (Fig. 4), we get noticeable differences. For example, the amplitudes of these EOF modes
(Fig. 6) are generally smaller than that from the observations and from the AMIP 18 individual members, and the sequence of the EOF modes is not the same either. The differences in sequence of these EOF modes shown in Figs. 4, 5 and 6 may indicate that either the observed sample size is not big enough or there is an impact of model biases. EOF1, EOF2, and EOF4 for the AMIP ensemble mean correspond to EOF4, EOF1 and EOF2, respectively, from the observations. The correlation coefficients of these three dominant modes with their counterparts from the observations are $0.52,0.55$ and 0.60 , respectively, and all of them exceed the 0.01 significance level (Table 2). However, a similar mode as EOF3 in the individual members and ensemble mean (Figs. 5c, 6c) doesn't appear in the first four modes of the observations (Fig. 4). That may suggest an impact of model biases and a lack of robustness of this mode.

Based on pattern correlation, it is noted that three out of the first four EOF patterns in the observations can be reproduced by the AMIP run either for the analysis based on individual members or on the ensemble mean. Also, it 

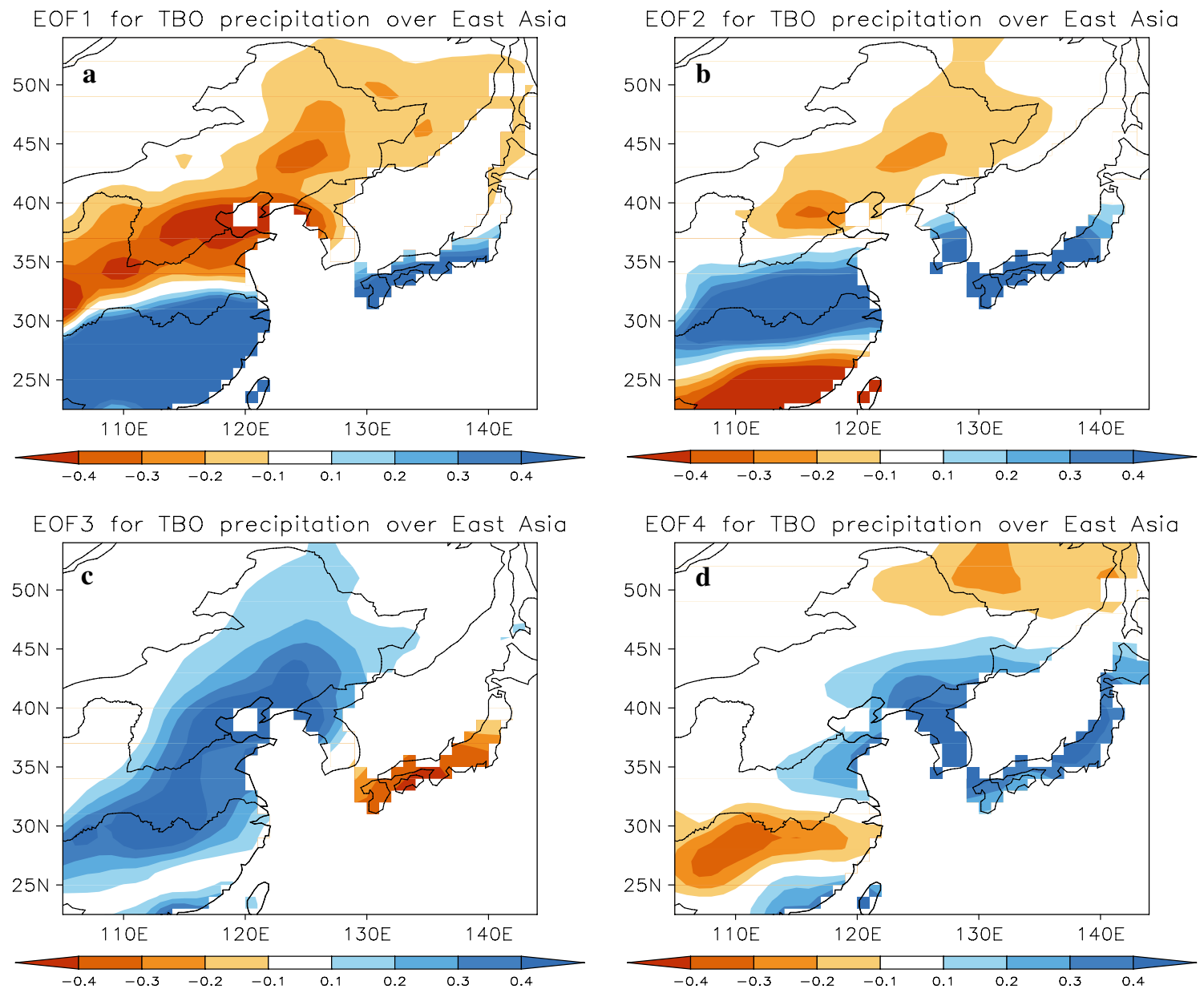

Fig. 5 Same as Fig. 4, but for the AMIP 18 individual members. EOFs 1-4 explain 25.6, 9.7, 5.8 and $5.0 \%$ of the total variance of TBO component, respectively

Table 1 Pattern correlations of leading EOF modes between the observations (Obs) and the AMIP individual 18 members (Ind)

\begin{tabular}{lcccc}
\hline ACC & Obs_EOF1 & Obs_EOF2 & Obs_EOF3 & Obs_EOF4 \\
\hline Ind_EOF1 & 0.30 & -0.01 & 0.41 & $\mathbf{0 . 5 5}^{*}$ \\
Ind_EOF2 & $\mathbf{0 . 6 8} *$ & 0.39 & -0.43 & 0.06 \\
Ind_EOF3 & -0.26 & $\mathbf{0 . 5 7} *$ & 0.10 & 0.14 \\
Ind_EOF4 & 0.11 & -0.27 & -0.01 & -0.27 \\
\hline
\end{tabular}

The bold number with “*” represents significance at 0.01 significant level using $T$ test

is evident that each pair of EOF patterns from the 18 individual members and the ensemble mean of the AMIP run is similar with pattern correlation coefficients of 0.98 , $0.69,0.55$ and 0.61 (Table 3), respectively. These significant pattern correlations indicate the fidelity of the AMIP simulations. However, it is clear that the amplitudes of EOF2-4 decreased substantially in the AMIP ensemble mean (Fig. 6), compared with those in the AMIP individual members (Fig. 5). These resemblances as well as the differences may further suggest that the TBO of rainfall in the EASM region is affected by both internal atmospheric processes and external forcing, such as SST. Following this, the connection of these EOF modes with SSTA is investigated further.

\section{Association of ENSO with leading EOF modes}

As mentioned in section "Introduction", existence of TBO in the Asian monsoon region is mainly the result of the ocean-land-atmosphere interaction; however, the contributions of the tropical oceans, especially ENSO, are also noticeable (Meehl and Arblaster 2002; Rasmusson et al. 1990; Yasunari 1990; Meehl et al. 2003). To further verify the connection of SSTA with TBO in the EASM region, we examine the lead-lag correlation of SSTA with the principal components (PCs) of TBO rainfall from the ensemble mean of the AMIP simulations and from the observations. 

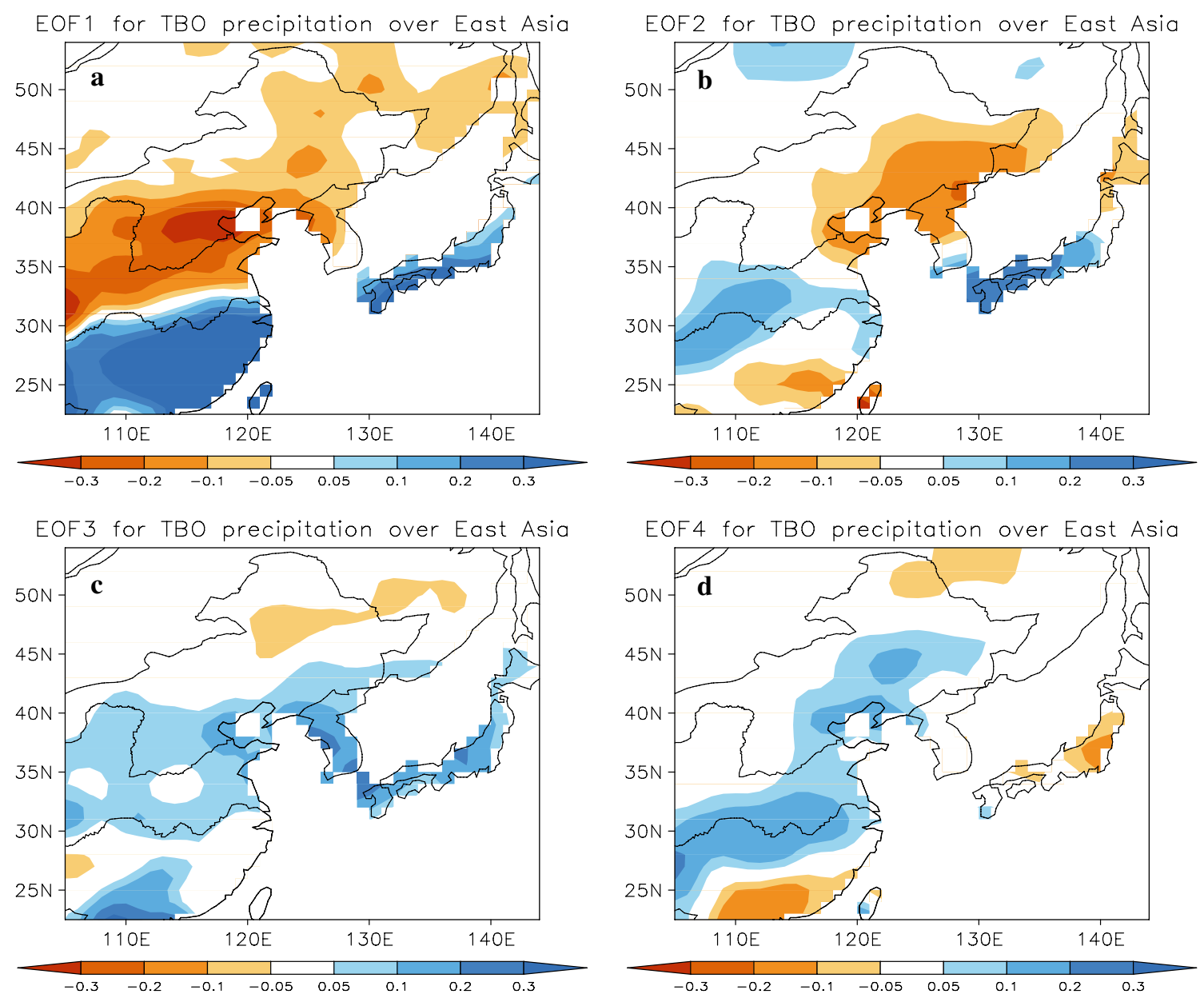

Fig. 6 Same as Fig. 4, but for the AMIP ensemble mean. EOFs 1-4 explain 29.6, 9.8, 7.4 and $6.5 \%$ of the total variance of TBO component, respectively

Table 2 Pattern correlations of the EOF modes between the observations (Obs) and the AMIP ensemble mean (Ens)

\begin{tabular}{llccc}
\hline & Obs_EOF1 & Obs_EOF2 & Obs_EOF3 & Obs_EOF4 \\
\hline Ens_EOF1 & 0.30 & -0.11 & 0.40 & $\mathbf{0 . 5 2}^{*}$ \\
Ens_EOF2 & $\mathbf{0 . 5 5}^{*}$ & 0.10 & -0.20 & 0.10 \\
Ens_EOF3 & 0.13 & -0.01 & 0.23 & -0.21 \\
Ens_EOF4 & 0.15 & $\mathbf{0 . 6 0}^{*}$ & -0.17 & 0.14 \\
\hline
\end{tabular}

The bold number with “*” represents significance at 0.01 significant level using $T$ test

SSTAs averaged in three key regions, Niño3: $5^{\circ} \mathrm{S}-5^{\circ} \mathrm{N}$, $150^{\circ}-90^{\circ} \mathrm{W}$ (Meehl and Arblaster 2002; Meehl et al. 2003), Pacific warm pool area (WP): $5^{\circ} \mathrm{S}-5^{\circ} \mathrm{N}, 120^{\circ}-160^{\circ} \mathrm{E}$ (Huang et al. 2006) and tropical western Indian Ocean (WIO): $5^{\circ} \mathrm{S}-5^{\circ} \mathrm{N}, 40^{\circ}-60^{\circ} \mathrm{E}$ (Chang and $\mathrm{Li} 2000$; $\mathrm{Li}$ et al. 2001), are used to represent the tropical ocean variability. Basing on the lead-lag correlations of these SST indices with PCs, we first identify the modes having significant
Table 3 Pattern correlations of the EOF modes between two types of AMIP simulation (individual 18 members and ensemble mean)

\begin{tabular}{lcccc}
\hline & Ind_EOF1 & Ind_EOF2 & Ind_EOF3 & Ind_EOF4 \\
\hline Ens_EOF1 & $\mathbf{0 . 9 8}^{*}$ & 0.05 & -0.17 & 0.06 \\
Ens_EOF2 & -0.07 & $\mathbf{0 . 6 9} *$ & 0.35 & 0.26 \\
Ens_EOF3 & 0.01 & -0.13 & 0.09 & $\mathbf{0 . 5 5} *$ \\
Ens_EOF4 & 0.03 & -0.39 & $\mathbf{0 . 6 1} *$ & -0.13 \\
\hline
\end{tabular}

The bold number with “*” represents significance at 0.01 significant level using $T$ test

correlation with ENSO. Then, relevant SSTA spatial patterns are isolated by the lead-lag linear regression of global SSTA onto the PCs of TBO rainfall from the ensemble mean of the AMIP run and from the observations. By comparing the similarity of the lead-lag correlation and the lead-lag regression of global SSTA in the AMIP run and in the observations, the robust and consistent relation of SST and the TBO in the EASM can be established. 

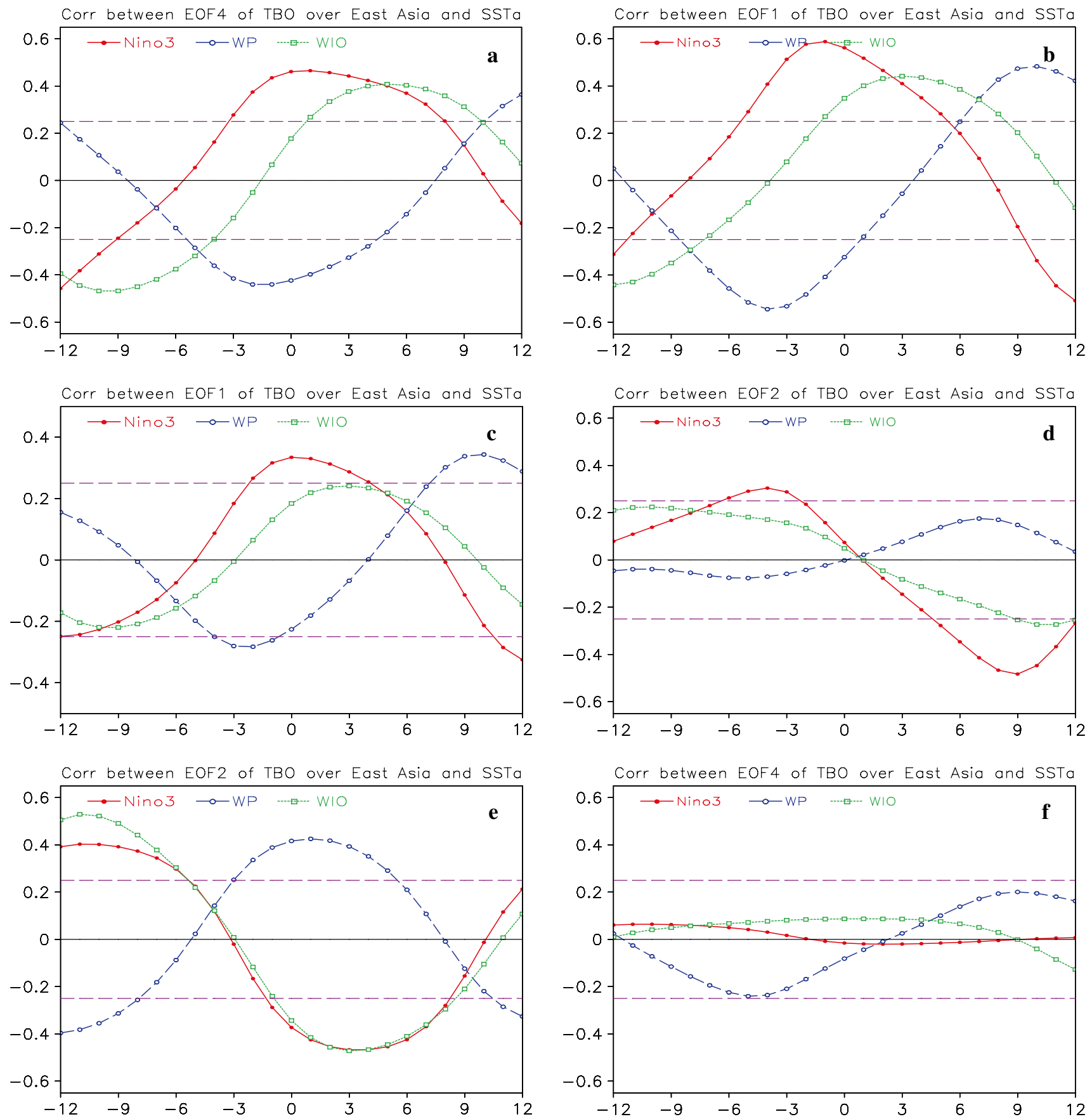

Fig. 7 Time-lag correlation of the PCs in the observations (a PC4; c PC1; e PC2) and their counterparts in the AMIP ensemble mean results (b $\mathrm{PC} 1$; d $\mathrm{PC} 2$; f PC4) with SSTAs in three key regions,

Based on the reproduction of the leading EOF modes in the AMIP run (Table 2), the analysis focuses on EOF1, EOF2 and EOF4 from the ensemble mean of the AMIP simulations and the observations. Figure 7 shows the leadlag correlations of three PCs (PC1, PC2 and PC4) from the observations (left column) and from the ensemble mean of respectively $(-\mathrm{N}(\mathrm{N})$ under the $\mathrm{x}$-axis denote the SSTA leading (lagging) $\mathrm{N}$ months to PCs). The purple dashed lines are the 0.05 significance level using $T$ test

the AMIP run (right column) with the SST indices in the three tropical regions: Niño3, WP and WIO.

As for the first pair of TBO PCs (PC4 from the observations and $\mathrm{PC} 1$ from the ensemble mean of the AMIP run), significant and consistent lead-lag correlations (Fig. 7a, b) are found in both the observations and the AMIP run, 

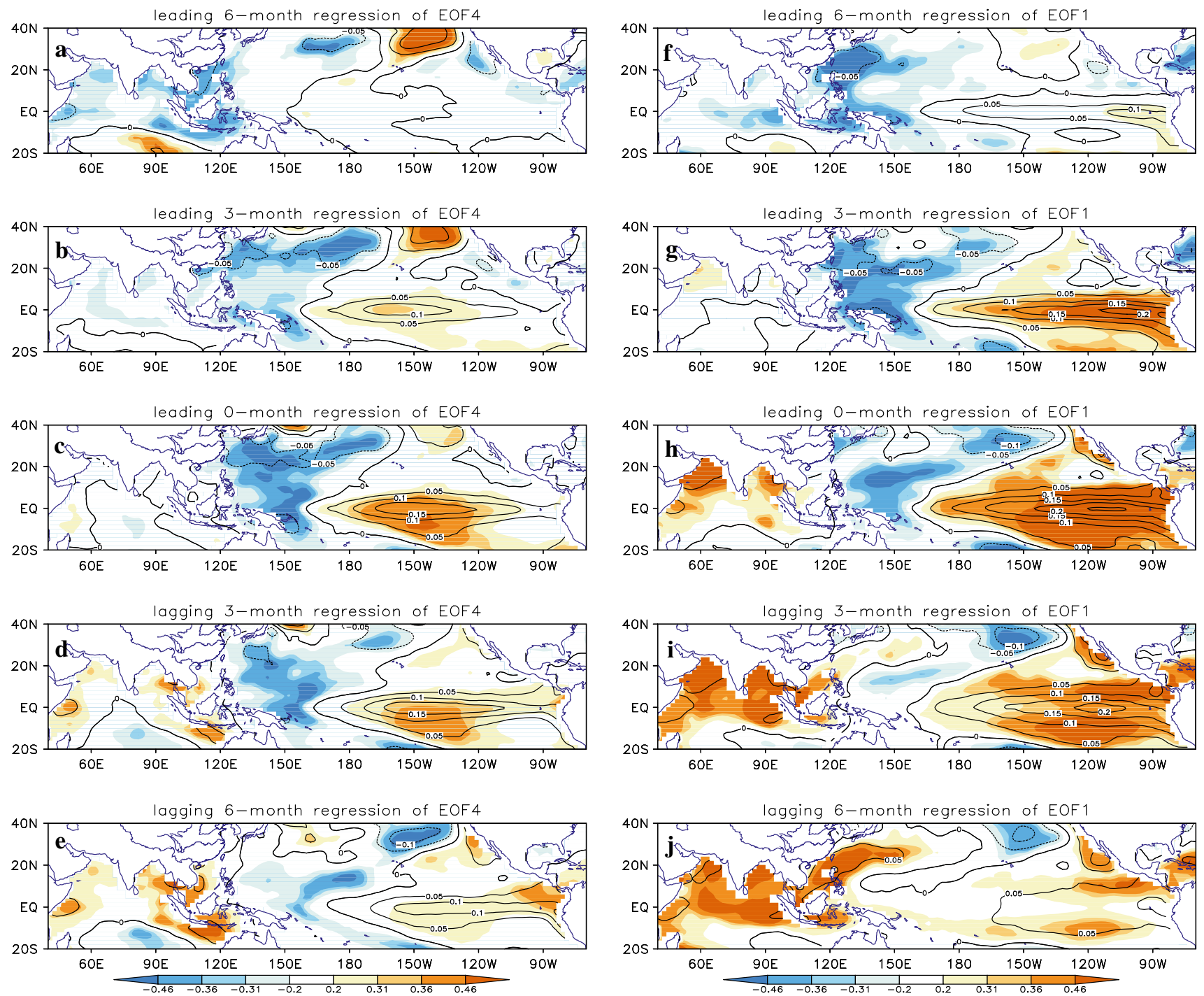

Fig. 8 Lead-lag linear regression of a PC4 of the observations (left column) and $\mathbf{b}$ PC1 of the AMIP (right column) with tropical Pacific SSTA. The regression coefficients are denoted by contours, and 0.1 ,

0.05 and 0.01 significance levels using $T$ test are shaded from light to dark colors, respectively

suggesting a robust connection of this EOF pattern of TBO rainfall with the tropical SSTA indices. The maximum correlation occurs when Niño3 and the PC are simultaneous (Fig. 7a, b). Since ENSO normally peaks in boreal winter, the simultaneous maximum correlation suggests that TBO rainfall in the EASM region is associated with ENSO development. According to the lead-lag correlations (Fig. 7a, b) and the EOF pattern (Figs. 4d, 6a), we note that when El Niño (La Niña) develops, northern China favors dry (wet) and southern China favors wet (dry) conditions at TBO time scales.

The connection of the TBO PC (PC4 from the observations and $\mathrm{PC} 1$ from the ensemble mean of the AMIP run) with ENSO is further assessed through linear regression of global SSTA onto the PC, both for the observations (left

column, Fig. 8) and for the ensemble mean of the AMIP run (right column, Fig. 8). For 6-months lead of SST, correlations are small, except for some negative values in the western Pacific and Indian Oceans. For 3-months lead, the ENSO-like pattern is visible, with positive correlations in the tropical central and eastern Pacific, and negative values in the western Pacific. The correlation reaches its peak in the tropical central and eastern Pacific for 0-month lead. The correlations then decrease when SST lags the PC.

Although the regressions with the PC from the observations and from the AMIP simulations (left and right columns of Fig. 8) are in good agreement, there are many differences in the details of locations and amplitudes of the regressions. For example, the positive regressions in the Indian Ocean and the tropical central and eastern Pacific 
are generally larger in the AMIP run than in the observations. This is probably because using the ensemble mean in the EOF computation for the AMIP run suppresses the SST-unrelated variability (i.e., the atmospheric internal variability) and enhances the variability associated with SST forcing. Furthermore, the regression patterns for the observations seem more like ENSO-Modoki, and those for the ensemble mean of the AMIP run are more analogous to the conventional ENSO (Ashok et al. 2007; Hu et al. 2012). Nevertheless, it is unclear if the spatial pattern difference is due to model bias or sampling, particularly for the observational analysis.

For the other two pairs of TBO PCs, the relationships with tropical SST anomalies are not well reproduced by the AMIP ensemble mean (Fig. 7c-f), although the spatial distributions of the EOF modes resemble the corresponding observations. The failure of the AMIP simulations in reproducing the possible link of these EOF modes of TBO rainfall in the EASM region with tropical SST may be caused by the influence of model biases. It may be also because the feedback of the atmosphere to the ocean is not included in the AMIP-type experiment. The air-sea interaction is particularly important for the summer climate in the western North Pacific (Wang et al. 2005, 2009; Zhu and Shukla 2013). Further, it is also possible that the connection in the observations might be obscured due to a small sample size.

\section{Summary and discussion}

Based on an ensemble AMIP run and observations, this study examined the characteristics and dominant spatial patterns of rainfall at TBO time scales over the EASM region and its association with ENSO. To some extent, the AMIP run well simulates the spatial distribution and amplitude of the TBO component. The average of the ensemble mean of the AMIP run increases the ratio of the TBO component to the raw data, which suggests that SSTA may enhance rainfall variations in the EASM region at TBO time scales.

Further investigation of the connection with SST indicated that only the EOF pattern at TBO time scales with opposite variations between northern and southern China had a robust relation with SSTAs in the tropical Pacific Ocean. Statistically, for development of El Niño (La Niña) events, northern China favors dry (wet) conditions while southern China favors wet (dry) conditions in TBO time scales.

There are other EOF modes in the observations having significant correlations with the SSTA in the tropical oceans, but the AMIP run was unable to reproduce the possible link. This may be partially caused by model biases, and also may be due to the fact that the feedback of the atmosphere to the ocean is prohibited in the AMIP-type experiment, while the feedback may be important for the summer climate variability in the EASM region (Wang et al. 2005; 2009; Zhu and Shukla 2013). The connections of SSTA with these EOF modes on TBO time scales in the observations need to be further verified either using a longer data record or based on different models to confirm the robustness of the connections as well as the robustness of the EOF modes (Dommenget and Latif 2002). Lastly, we note that the summer rainfall in the EASM region seems largely driven by internal dynamical processes. Thus, it is still a challenge to incorporate the relationship between ENSO and TBO time scale rainfall variation into operational forecasts of the eastern Asian summer rainfall, since the overall statistical relationship between ENSO and the summer rainfall variations over East Asia are weak (Wu et al. 2003).

Acknowledgments This work was supported jointly by the National Special Science Research Project (2012CB955203), the National Basic Research Program of China (2012CB417205), the National Natural Science Foundation of China (41005037), and China Meteorological Administration R\&D Special Fund for Public Welfare (Meteorology) (GYHY201306033, GYHY201306024). The lead author (Y. Liu) also thanks the support of the National Innovation Team of Climate Prediction of China Meteorological Administration. Most of this work was conducted when Liu visited the NOAA/NCEP Climate Prediction Center. The authors appreciate the constructive comments and suggestions from two reviewers, which significantly improved the quality of this paper.

Open Access This article is distributed under the terms of the Creative Commons Attribution License which permits any use, distribution, and reproduction in any medium, provided the original author(s) and the source are credited.

\section{References}

Ashok K, Behera SK, Rao SA, Weng H, Yamagata T (2007) El Niño Modoki and its possible teleconnection. J Geophys Res 112:C11007. doi:10.1029/2006JC003798

Chang CP, Li T (2000) A theory of the tropical tropospheric biennial oscillation. J Atmos Sci 57:2209-2224

Chang CP, Zhang YS, Li T (2000) Interannual and interdecadal variations of the East Asian summer monsoon and tropical Pacific SSTs. part I: roles of the subtropical ridge. J Clim 13:4310-4340

Chen MY, Xie PP, Janowiak EJ, Arkin AP (2002) Global land precipitation: a 50-y monthly analysis based on gauge observations. $\mathrm{J}$ Hydrometeor 3:249-266

Ding YH (2007) The variability of the Asian summer monsoon. J Meteor Soc Jpn 85:21-54

Ding YH, Wang ZY, Sun Y (2008) Interdecadal variation of the summer precipitation in East China and its association with decreasing Asian summer monsoon. Part I: observed evidences. Int J Climatol 28:1139-1161

Dommenget D, Latif M (2002) A cautionary note on the interpretation of EOFs. J Clim 15:216-225

$\mathrm{Hu} \mathrm{Z}-\mathrm{Z}$ (1999) Interannual variability of summer climate mode over East Asia and its mechanism. Acta Ocean Sin 21:26-39 
Hu Z-Z, Kumar A, Jha B, Wang W, Huang BH, Huang BY (2012) An analysis of warm pool and cold tongue El Niños: air-sea coupling processes, global influences, and recent trends. Clim Dyn 38:2017-2035. doi:10.1007/s00382-011-1224-9

Huang JY (1988) The representations of the tropospheric biennial oscillation in precipitation over China. Chin J Atmos Sci 12:267273 (in Chinese)

Huang RH, Chen JL, Huang G, Zhang QL (2006) The quasi-biennial oscillation of summer monsoon rainfall in East China and its cause. Chin J Atmos Sci 30:545-560 (in Chinese)

Kumar A, Barnston AG, Hoerling MP (2001) Seasonal prediction, probabilistic verifications, and ensemble size. J Clim 14:1671-1676

Kumar A, Chen M, Zhang L, Wang W, Xue Y, Wen C, Marx L, Huang B (2012) An analysis of the non-stationarity in the bias of sea surface temperature forecasts for the NCEP climate forecast system (CFS) version 2. Mon Weather Rev 140:3003-3016

Lau KM, Wu HT (2000) Principal modes of rainfall-SST variability of the Asian summer monsoon: a reassessment of the monsoonENSO relationship. J Clim 14:2880-2895

Lau KM, Yang S (1997) Climatology and interannual variability of the Southeast Asian summer monsoon. Adv Atmos Sci 14:141-162

Li T, Tham CW, Chang CP (2001) A coupled air-sea-monsoon oscillator for the tropospheric biennial oscillation. J Clim 14:752-764

Li T, Liu P, Fu X, Wang B (2006) Spatiotemporal structures and mechanisms of the tropospheric biennial oscillation in the IndoPacific warm ocean regions. J Clim 19:3070-3087

Li CY, Pan J, Que ZP (2011) Variation of the East Asian Monsoon and the tropospheric biennial oscillation. Chin Sci Bull 56:70-75

Liu YY, Ding YH (2012) Analysis of the leading modes of the AsianPacific summer monsoon system. Chin J Atmos Sci 36:673-685 (in Chinese)

Liu YY, Ding YH, Gao H, Li WJ (2013) Tropospheric biennial oscillation of the western Pacific subtropical high and its relationships with the tropical SST and atmospheric circulation anomalies. Chin Sci Bull 58:3664-3672

Meehl GA (1994) Influence of the land surface in the Asian summer monsoon: external conditions versus internal feedback. J Clim 7:1033-1049

Meehl GA (1997) The South Asian monsoon and the tropospheric biennial oscillation. J Clim 10:1921-1943

Meehl GA, Arblaster JM (2002) The tropospheric biennial oscillation and Asian-Australian monsoon rainfall. J Clim 15:722-744

Meehl GA, Arblaster JM, Loschnigg J (2003) Coupled ocean-atmosphere dynamical processes in the tropical Indian and Pacific Ocean regions and the TBO. J Clim 16:2138-2158

Mooley DA, Parthasarathy B (1984) Fluctuations in All-India summer monsoon rainfall during 1871-1978. Clim Change 6:287-301

Nitta T, Hu Z-Z (1996) Summer climate variability in China and its association with $500 \mathrm{hPa}$ height and tropical convection. J Meteor Soc Jpn 74:425-445

North GR, Bell TL, Cahalan RF, Moeng FJ (1982) Sampling errors in the estimation of empirical orthogonal functions. Mon Weather Rev 110:699-706

Qiao YT, Jian MQ, Luo HB (2005) Tropical biennial oscillation of moisture sink over Asian-Australian monsoon region and its relationship with atmospheric circulation. Acta Sci Nat Sun Yatsen Univ 44:98-101 (in Chinese)

Rasmusson EM, Wang XL, Ropelewski CF (1990) The biennial component of ENSO variability. J Mar Sys 1:71-96

Reed R, Cambell WJ, Rasmusson LA, Rogers DG (1961) Evidence of a downward propagating annual wind reversal in the equatorial stratosphere. J Geophys Res 66:813-818

Saha $\mathrm{S}$ et al (2014) The NCEP climate forecast system version 2. J Clim 27:2185-2208. doi:10.1175/JCLI-D-12-00823.1

Shen S, Lau KM (1995) Biennial oscillation associated with the East Asian monsoon and tropical sea surface temperatures. J Meteor Soc Jpn 73:105-124

Smith TM, Reynolds RW, Peterson TC, Lawrimore J (2008) Improvements to NOAA's historical merged land-ocean surface temperature analysis (1880-2006). J Clim 21:2283-2296

Tian SF, Yasunari T (1992) Time and space structure of interannual variations in summer rainfall over China. J Meteor Soc Jpn 70:585-596

Wang JX, Lu JN, Shi YG (1995) Quasi-biennial oscillation of wet season precipitation in the upper and middle reaches of the Yangtze River. J Nanjing Inst Meteor 18:229-233 (in Chinese)

Wang B, Wu R, Fu X (2000) Pacific-East Asia teleconnection: how does ENSO affect East Asian climate? J Clim 13:1517-1536

Wang B, Wu R, Lau KM (2001) Interannual variability of Asian summer monsoon: contrasts between the Indian and Western North Pacific-East Asian monsoons. J Clim 14:4073-4090

Wang B, Ding Q, Fu X, Kang IS, Shukla J, Doblas-Reyes F (2005) Fundamental challenge in simulation and prediction of summer monsoon rainfall. Geophys Res Lett 32:L15711. doi:10.1029/20 05GL022734

Wang B et al (2009) Advance and prospect of seasonal prediction: assessment of the APCC/CliPAS 14-model ensemble retrospective seasonal prediction (1980-2004). Clim Dyn 33:93-117

Wu R, Hu Z-Z, Kirtman BP (2003) Evolution of ENSO-related rainfall anomalies in East Asia. J Clim 16(22):3742-3758

Wu Z, Schneider EK, Kirtman BP (2004) Cause of low frequence North Atlantic SST variability in a coupled GCM. Geophys Res Lett 31:L09210. doi:10.1029/2004GL019548

Yasunari T (1990) Impact of Indian monsoon on the coupled atmosphere ocean system in the tropical Pacific. Meteor Atmos Phys 44:29-41

Zhan FX, Liu YY, He JH (2013) Tropospheric biennial oscillation of the precipitation over Jiangnan area of China in Spring and its relationship with the tropical SST anomaly. Sci Geogr Sin 33:1006-1013 (in Chinese)

Zhu J, Shukla J (2013) The role of air-sea coupling in seasonal prediction of Asian-Pacific summer monsoon rainfall. J Clim 26(15):5689-5697. doi:10.1175/JCLI-D-13-00190.1 